\title{
Neurotrophic keratitis presenting in infancy with involvement of the motor component of the trigeminal nerve
}

\author{
J D Heath, G Long
}

We report a case of unilateral congenital corneal anaesthesia presenting in a 5-year-old girl, where computed tomography (CT) elegantly demonstrated corresponding motor involvement of the first division of the ipsilateral trigeminal nerve, and helped to confirm the diagnosis.

\section{Case report}

A 5-year-old girl was referred to our ophthalmology department by her general practitioner having failed a school medical sight test. Her only symptom was blurring of vision of the left eye, and in particular she had experienced no pain or redness. She had been delivered at term by caesarean section for fetal distress, and had no neonatal problems. She had two short admissions to hospital for failure to thrive and an upper respiratory tract viral infection. She had been fully vaccinated, and there was no history of atopy.

On examination, her right visual acuity was $6 / 6$ and the left was 6/9. There was a punctate epithelial keratitis of the left cornea with absent left corneal sensation. The eye was white and quiet. The cutaneous sensation of the first division of the left trigeminal nerve was slightly reduced and the jaw jerk appeared normal. A slight left ptosis was noted, which had been present since birth, and had not progressed. The third, fourth, sixth, and seventh cranial nerves were normal.

University Hospital of Wales, Heath Park, Cardiff CF4 4XW

Ophthalmology

Department

$J$ D Heath

Radiology Department G Long

Correspondence to:

J D Heath.

Accepted for publication 18 May 1993

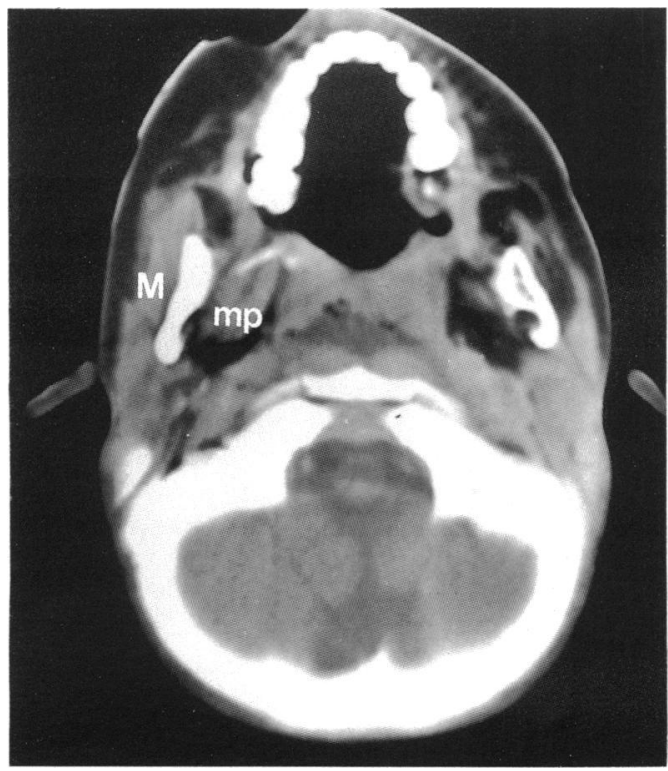

Figure 1 Contrast enhanced axial computed tomographic image at the level of the oropharynx and maxilla. Normal right masseter muscle $(M)$ and right medial pterygoid muscle ( $m p$ ) with atrophy of the corresponding muscles on the left (on nght) in picture.

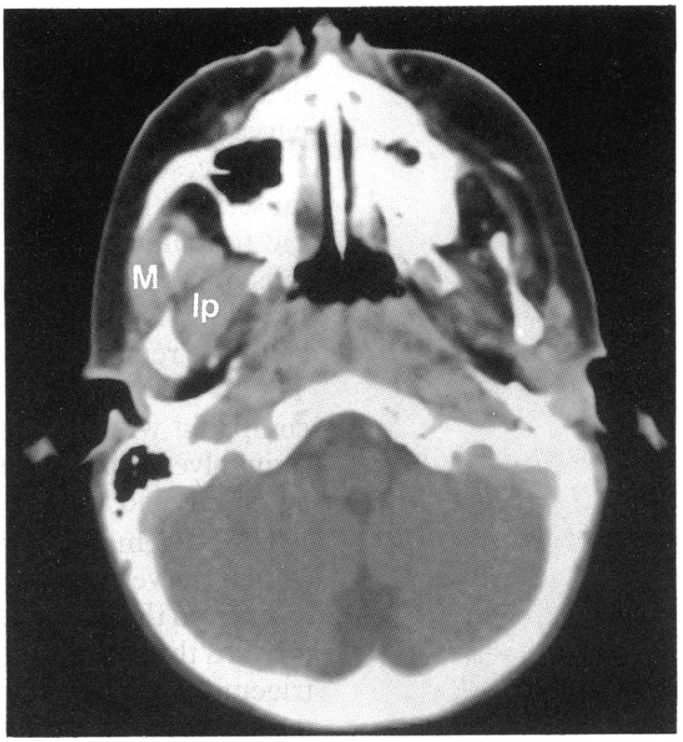

Figure 2 Contrast enhanced axial computed tomographic image at the level of the nasopharynx. Normal right masseter (M) and right lateral pterygoid muscle (lp) with atrophy of the corresponding muscles on the left (right).

A diagnosis of corneal anaesthesia was made and she was treated with ocular lubricants.

A CT scan under general anaesthesia was performed (Figs 1, 2, and 3) to exclude a new lesion of the brain stem, pons, or cerebellum. Contiguous axial images were obtained, both pre and post intravenous contrast enhancement, from the level of the hard palate to the vertex.

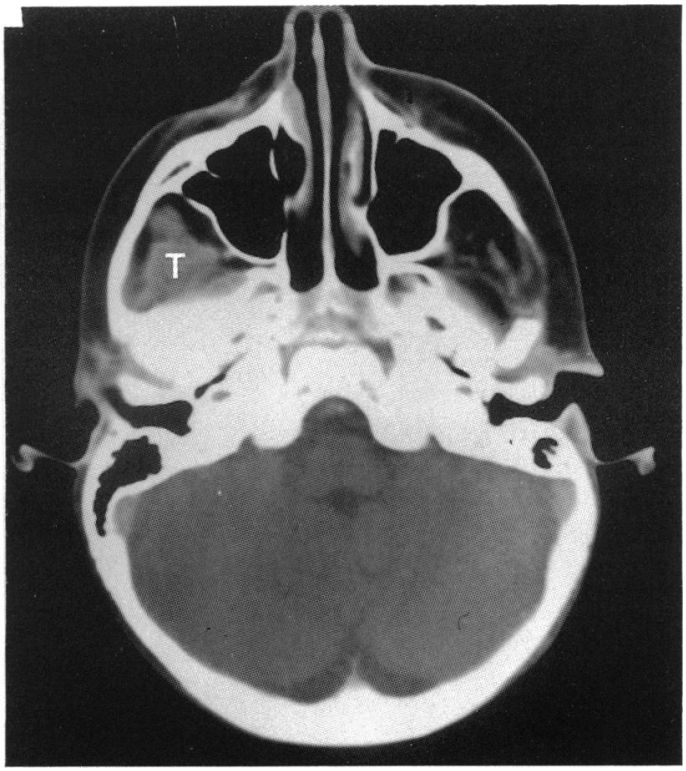

Figure 3 Contrast enhanced axial computed tomographic image at the level of the optic nerves. Normal right temporalis muscle $(T)$ with atrophy of the corresponding muscle on the left (right). 
At her first review 2 weeks after diagnosis, and at review 2 months later, asymptomatic subtarsal foreign bodies were removed. Patient follow up at 10 months showed an improvement in the left corneal epithelial keratitis.

\section{Comment}

This 5-year-old girl appears to have a congenital absence of both sensory and motor components of the left trigeminal nerve. The sensory impairment was suggested clinically by the keratitis associated with corneal anaesthesia, and the absence of any other corneal pathology. The defect of the motor component of the trigeminal nerve only became apparent after the CT scan. The investigation demonstrated atrophy of the muscles on the left supplied by the motor root of the trigeminal nerve - namely, the left temporalis, masseter, and medial and lateral pterygoid muscles. Loss of neural input produces atrophy and fatty replacement of the denervated muscle. This is shown by the marked asymmetry when compared with the muscles of the contralateral uninvolved side. This had not been clinically apparent, and added support to the diagnosis.

The trigeminal nerve is the largest of the cranial nerves and arises in sensory and motor roots from the lateral aspect of the pons. It passes forward through the posterior fossa and ioins the trigeminal ganglion which lies in a bony fossa at the apex of the petrous temporal bone. The three divisions of the trigeminal nerve are given off from its anterior border. The nasociliary nerve is the first branch of the first division and gives off the sensory root to the ciliary ganglion which contains sensory fibres from the cornea, iris, and ciliary body. The motor portion of the trigeminal nerve has no connection with the trigeminal ganglion and passes with the third division through the foramen ovale to supply the medial and lateral pterygoid muscles, temporalis, and masseter.

Corneal anaesthesia may follow any cause of fifth nerve damage. Common causes are herpes zoster ophthalmicus, trauma, lesions of the brain stem and pons, and cerebellopontine angle tumours. The likely aetiology of the keratitis is reduced blinking and reflex tear production, resulting in corneal drying and repeated trauma. Fetal rabbit trigeminal neurons have been demonstrated to influence the production of type VII collagen in vitro. ${ }^{1}$ Type VII collagen is a major component of the anchoring fibrils involved in the attachment of the corneal epithelium to the underlying stroma. Corneal hypoaesthesia can occur as an isolated abnormality, or in conjunction with trigeminal hypoaesthesia, particularly of the first division. It may be unilateral, ${ }^{2}$ or familial. ${ }^{3}$ Corneal anaesthesia may be part of a more widespread anaesthesia, ${ }^{4}$ but is more often confined to the cornea. ${ }^{5}$ It has been described in association with leprosy, ${ }^{6}$ and in a milder form in Adie's pupil, ${ }^{7}$ and in some corneal dystrophies. ${ }^{8}$ In any severe keratitis, the corneal sensation will tend to be reduced.

The mainstay of treatment of neurotrophic keratitis is topical antibiotics in the acute stage, followed by long term ocular lubricants. Severe cases may require lateral tarsorraphy. Visual deprivation amblyopia may occur owing to corneal scarring, viscous ocular lubricants, or tarsorraphy.

The authors would like to acknowledge C M Lane, S Wallace, and $M$ Hourihan for their help.

1 Baker KS, Anderson SC, Romanowski EG, Thoft RA, Raj NS Trigeminal ganglion neurons affect corneal epithelial phenotype. Invest Ophthalmol Vis Sci 1993; 34: 137-44.

2 Stewart HL, Wind CA, Kaufman HE. Unilateral congenital corneal anaesthesia. Am $\mathcal{F}$ Ophthalmol 1972; 74: 334-5.

Purcell JJ, Krachmer JH. Familial corneal hypesthesia. Arch Ophthalmol 1979; 97: 872-4.

4 Manfredi M, Bini G, Cruccu G, Accornero N, Berardelli A Medolago L. Congenital absence of pain. Arch Neurol 1981; 38: $507-12$.

5 Hewson GE. Congenital trigeminal anaesthesia. $\mathrm{Br} 7$ Ophthalmol 1963; 47: 308-11.

Shields JA, Waring GO, Monte LG. Ocular findings in leprosy Am f Ophthalmol 1974; 77: 880-90.

7 Purcell JJ, Krachmer JH, Thompson HS. Corneal sensation in Adie's pupil. Am f Ophthalmol 1977; 84: 496-500.

8 Birndhorf LA, Ginsberg SP. Hereditary fleck dystrophy associ ated with decreased corneal sensitivity. Am $\mathcal{f}$ Ophthalmol 1973; 73: 670 